\title{
ARE MUSEUMS PUTTING HERITAGE UNDER THE DOMINATION OF THE TOURISM INDUSTRY?
}

\section{Priscilla Boniface}

The complex relationship between museums, heritage and tourism is discussed. Consideration is given to whether museums heritage and old style method of operation can reasonably continue, and how heritage is and can be treated by museums. It is regarded as essential for museums to show contemporary relevance. They need to be used and valued by the range of society and should show that they are focused upon all types of visitor. Tourists are suggested to be, essentially, visitors, and not therefore a sector apart causing fear and trepidation.

The discussion is about whether tourism is subjecting museums and the heritage they present to inappropriate and unhelpful influence. Conversely, it is considered whether museums see tourism as a fearful threat to be resisted if they are to maintain their integrity and role.

What is the heritage that tourism might be threatening? Perhaps the heritage loss feared by museums and their curators is in these areas:

a) an intrusion, of ignorance and misunderstanding, upon an accepted position of responsibility to choose what matters in a museum provision;

b) a distortion of the traditional museum role from the influence of tourism because of others' hope in its supposed benefits and insistence therefore, upon provision of 'what the punter wants'; c) a fundamental change in tenets and practice of museum outlook and operation.

Museums' trepidation therefore would be about two kinds of threat:

1) to the 'objectivity' and professionalism of choosing the heritage to be presented;

2) to the traditional style of operation.

But perhaps museums' heritage worries about tourism also betray museums own insecurity. Perhaps they feel inadequate and fear their own capacity to change and cope with a situation changing and changed around them?

Museums' inheritance is that they are containers of collections. To realise their objectives of keeping and caring for objects, of serving as a storehouse of items for future generations, of making know- 
26 ledgeable presentations about collections, a museum profession developed, with personnel expert in conservation and maintenance, and in research into objects and their context. A difficulty now is that, though certain fundamentals remain, to these have been added other and more pressing priorities.

As with any heritage item, the dilemma, not always readily visible to those with immediate goals in their sights, is to decide and achieve the suitable and correct balance between showing adequate current relevance while planning and managing appropriately to keep a presence for the future.

Two heritage aspects in relation to museums and tourism therefore need evaluation. The first is how the museum itself can adapt to changing circumstances; the second is how heritage should feature as a museum subject. The consideration here uses the museum visitor as its object and derivation. And a very broad definition of tourist, useful in a museum contexts, equates the tourist with the visitor. The tourist is depicted by Davidson (1994: 23) 'as a person travelling outside of his/her normal routine - either normal living or normal working routine; and since he is speaking in relation to economic development/impact he adds 'who spends money'. A tourist to a museum can be regarded as anyone visiting a museum, though there are subdivisions of holidaymakers such as business tourists, day visitors, those on overtly educational visits and visitors from an immediate vicinity. In the category of holidaymaker, by implication, pleasure seeker, are probably those whom museums might see as tending to threaten them.

Museums are understandably imbued with an idea of their traditional role and the preoccupations of their discipline. In general museums have been slow to develop a humility and an understanding of their consumers or to identify how best to establish communication with them. That position, leaning to arrogance, has lost them friends and attendees. To say so is to recognise a wider constituency, the audience to be accounted to beyond those who might at the museum's portals. A museum has a range of stakeholders' support to win and keep, ranging from funders to the residents of its surroundings. A social role is a traditional one for a museum. Contemporary society's needs of the museum have not perhaps been sufficently identified or catered to. The museum would say, and rightly so, that its functions are to serve succeeding generations as well as those of the present. However, if only to avoid ceasing to exist through public perception of its uselessness, the museum needs to show that it serves the society of its current time. This is not to say a museum should sell its soul but merely to insist that it must demonstrate a contemporary function. Museums' heritage of implicit elitism and failure to show value to the whole of society is not an acceptable position for nowadays. Key questions to be answered must be: 'How can museums avoid being obsolescent, redundant, heritage artefects?'; 'What are museums for, now and for the future?'; 'Who are they for?'.

The museum is, essentially, a provider. Though it may regard itself as presenting objects, essentially what it is delivering is information. And in the public perception, this is a 'trump card' for museums; the information they disseminate is regar- 
ded from outside as authoritative and balanced. A museum is visited to obtain truth and imbibe authenticity. The public's guard, up in the outside world suspicious of yarn or fable for commercial or other motives, is relaxed in a museum because of an expectation of veracity. The museum fraternity, however, with its knowledge of some motivations to collect and display and the objectives of aggrandisement, polemic, and special pleading, for which museums and their collection have sometimes been pressed, may not be quite so trusting.

The audience of a museum is diverse. It falls, however, essentially, into two categories. One is the actual visitors, museums' tourists. The other is its range of stakeholders. To the first group, which is divisible into many sub-categories, the museum essentially provides a service. The services it provides need to be seen as benefits by its users. To the second group their participation in, and support of, a museum's existence is also for perceived benefits, ranging enormously in type. Public sector support and involvement in museums is now usually to achieve economic development or regeneration perceived as likely to accrue, directly or indirectly, from the existence and activity of a museum. Other motives of involvement, often associated, are those of status and image. A museum with a noticeable and appealing presence serves to deliver to its home location, often situated in a competitive position with other places, cachet and distinctiveness.

To produce the necessary benefits to its various groups, the museum must focus upon each of the several sectors and determine and understand their needs of the museum. Tourists certainly expect, and visitors mostly overall want, to enjoy and be entertained by a museum visit and all that goes with it. This may worry a museum professional because of a concern that a need to deliver enjoyment and entertainment may result in the distortion or avoidance of information and the delivery of an imbalance or an inaccurate interpretation. This probably points at the fundamental reason why tourists as museum visitors are regarded by museums with diffidence and apprehension. There is requirement too for the other needed facets of the contemporary good outing such as eating and cloakroom facilities of good standard, available seating on which to rest, disabled access and so on. A museum shop is not only an important item from the perspective of the museums' needs because of the income generation potential but is a desirable item in the visitors' eyes. All are part of the experience, and to appeal to visitors the experience needs to be attractive. Museums are in competition with the range of leisure experiences and they need to accept and cater to this.

Society's character and demography are critical to determining 'products' with appeal. Relevant to museum visiting now and into the future is the emergence of a large 'grey' and relatively affluent market. This is likely to represent a consumer band placing a premium on quality and willing to spend a premium price to obtain it. Critical for consideration, and this may be to suggest an aspect of worry to the museum profession, is to consider and know the values by which a segment operates, to provide presentations commensurate with these. It is also important 
28 to know what value is placed on museum visiting. Grey consumer power could result in museums retaining an ancient 'heritage' way of operation and providing presentations on subjects of relevance and appeal to the older generation so as to be successful and visited by this key and potentially lucrative market. But what is to cater to the younger generation with its different tastes and interests? Some tourists would not desire to go anywhere near a museum, and if museums want or have the necessity to attract them, they need to understand why not. They probably also need to change internal attitudes which may be causing a deterrent through the type of material and facility offered. As the Area Museum Council for the South West and the West Country Tourist Board (1993:6) commented:

The barriers are mostly in people's minds; there are prejudices against museums, which are sometimes perceived as boring, and there are those who consider tourists as a scourge.

In more forthright tone, distinguishing a crucial, and probably strongly felt and underlying perception of museums, Marshall McLuhan delivered the swinging criticism (1969:65):

Blast those art galleries and museums which imprison and classify human spirit.

Perhaps such an attitude as McLuhan portrays is among features responsible for an apparent shift of emphasis towards museums communicating contemporaneity. For the moment the balance seems to be with museums and galleries which are overtly modern. Denmark, for example, opened a new Museum of Modern Art, Arken, for its year as European Cultural Capital; Stockholm similarly is doing so in 1998. Even the tiny island of Bornholm, following the style of Lousiana, Denmark's earlier exercise in modernity, has opened a new Art Museum. It seems as if the message is that such buildings are not stuffy and stultifying and that they are daring. The reasons for this are likely to lie among the attitudes and needs of audiences of museums described above. For museums to serve the purposes of attracting tourists, of acting as encouragement to economic development, for delivering new pride in a total resident community, they need to be obviously visible and sensational and speak their message loudly. This presentation needs to include, and be especially to, initial outsiders to museums' doors. Looking as examples at two mega museums, both opened in the autumn of 1997, the Guggenheim at Bilbao, and the Getty in Los Angeles, it is possible to identify some such phenomena at work. Both are externally eye-catching, as by the criteria described they must be. Importantly and relevantly, both are named with globally known 'brands'. In the instance of the former, for the benefits of the brand and the belief in its following and opportunity, the Basque authorities courted Thomas Krens the Guggenheim Foundation's entrepreneurial Director and paid for the attraction, the third such Guggenheim (others being in New York's SoHo and in Venice) to be established at their location. The Bilbao Guggenheim depicts itself (World Wide Web July 1997: 4) as an 'international landmark'. The Getty Center, showing its recognition of serving a many-sided and contemporary role and 
market, describes itself (World Wide Web December 1997: 1) as

a crossroads for families and neighbors, scholars and students, tourists and teachers. It's a place for fun and reflection, overlooking one of the world's most exciting cities.

To serve their social role in a society which espouses democracy, and perhaps particularly because of the general ascendancy of capitalism and privatisation, museums have shown themselves willing to become public meeting places. Sometimes this has been imposed upon them in the absence of many other candidates but nevertheless this role serves to counteract a perceived polarisation of public and visitor brought to attention by museum critics. Perhaps the first modern, in both senses, example of the type is the Pompidou Centre. Symbolically its stairways are external to the building and visible for all to see. Famously, a public arena has come to appear in front of this Paris museum.

Heritage now seems to be rather 'on the back-burner' and perhaps it needs to be to meet the visitor and stakeholder, entertainment and developmental, needs described. But heritage has a role in meeting society's needs. Heritage, the past, cannot be excluded from museums' attention and agenda. It has too many important messages today's society needs to know, be reminded of, and learn lessons from. Washington's Holocaust Museum is a particularly powerful exemplification of this. And as we know, a global - local pendulum swing and interaction is manifest in today's world. As counterpoint to homogenisation and globalisation, society seeks to recognise its roots and acquire a sense of identity. In a multi-cultural environment it is important that an understanding of others' cultures be imbued to generate a tolerance that we may all develop. Tourism is a strong and crucial feature in that process. The USA Partners in Tourism: Culture and Commerce publication (1997: 5) comments:

The potential of cultural tourism to spark economic dynamism in rural settings as well as urban areas results from a demographic shift that sees the "baby boomers" turning inward to explore their own identity by investigating not only their own roots, but the nation's vibrant multicultural context as well.'

In the introduction to the USA publication (1997:1), the President of the American Association of Museums opines positively and confidently,

Cultural organisations can satisfy the traveler's desire to get to know a particular place, its people and their story.

Tunbridge and Ashworth (1996:66), however, have warned that it is not easy to develop a bridge of understanding and interest between the tourist and a local culture, saying,

if heritage is a demand-defined product ... then tourist-defined heritage will be selected according to the expectations of the visitor. It can be assumed that these expectations will be substantially different from those of the resident because they will have been shaped by a quite different set of circumstances. We arrive at the adage that "you cannot sell your heritage to tourists: you can only sell their heritage back to them in your country». The local 
30 experience has to be incorporated into the visitor's existing heritage. The unfamiliar is sellable in so far as it can be reached through the familiar: if what is familiar is different then so also is the heritage selected.

This suggests that using heritage for tourism represents a very considerable challenge.

That the challenge of communicating about cultures requires to be met in our society's developmental interest was a message of the World Decade of Cultural Development when it reported (1987: 18),

The recognition by the international community of the need to place culture at the centre of development is already beginning, though not yet widely, to be reflected in practical terms.'

Eleven years on, the message is still resonant to and important for the museums tourism heritage relationship and exchange.

The museum ought to remind itself it only collects, cares and conserves, to provide for others. Museums are not there for themselves as providers. So, museums must demonstrate accessibility, in every sense. This means that their style and demeanour must be one of approachability in all terms: their information needs to accommodate the breadth of age levels and personality types and the full range of extent of learning and enquiry: their environment needs to be such as to be able to accommodate all types of physical disadvantage and impairment. Such situations in Western society as the breakdown of the nuclear family and the consequential changes of needs, should find reflection in museums' provision. Specific factors for attention in meeting needs and showing relevance, such as times of opening hours and whether admission is free or not, are matters demanding careful decision in demonstrating and providing access. That museums can no longer be as in the past is essential. As Thomas Krens has stated (Guggenheim Magazine Fall 1997:8 as reported by Slessor December 1997:5.)

That the museums of the future will no longer resemble the familiar institutional and social form that has quietly and persistently evolved over the past 200 years is a foregone conclusion.

This is not to say that museums must destroy their own heritage of how they operate. Mulgan (1997: 32) has said 'Each new medium of communication does not displace its predecessors so much as complement them.' There is room in society for old and new. New should not obliterate old, provided old is fashioned and handled to meet modern needs. The old museum can adapt but keep its principles, provided it delivers a message of modern relevance and in a style, and from a starting point, so as to establish contemporary contact. Distortion of information and prostitution of integrity do not necessarily follow from catering extensively. And as Boyd (1992) points out, concerning the need for museums to serve a wide spectrum,

The issue is not showmanship versus scholarship; rather, the issue is how to convey scholarship to a diverse public.

For a productive relationship, museums and the tourism industry need to under- 
stand each others' concerns and priorities and to recognise each others' areas of expertise. It is explained in the publication, for the UK Museums \& Galleries Commission with co-operation from The English Tourist Board, Museums and Tourism: Mutual benefit (Runyard 1993:4),

Museums are seen by tourism organisations from a particular perspective, and it is one which does not always encourage mutual understanding. The only interest which a tourist board or operator could possibly have in a museum is as a visitor attraction. While they may have interest in well presented collections, they have no interest in collections management. [...] The gap in understanding, and the difference of priorities is one which endangers effective cooperation.

In the USA the top level 'Partners in Tourism: Culture and Commerce' coalition has been established. In its publication is a comment (1997: vi) of retrospection and realism, showing the usefulness of dialogue and discussion. Executive Director of the California Council of the Humanities, James Quay, writes

Culture and tourism began as uneasy, even contentious partners. Cultural institutions like museums tend to be driven by missions and an urge to educate, while tourism is driven by markets and the profit motive. A marriage between the two is often driven by economic opportunity rather than natural affinity and, like any relationship, requires a lot of talking and listening to ensure understanding.

Among the initiatives, the American Association of Museums ran, Able (1997: 2) describes, 'regional cultural tourism leadership forums.' The implications con- cerning types and style of museum training are clear and obvious. Further messages of the necessity for training to be given to cater for tourists is in the UK Museums Association's 1996 strategy document. All in all, partnership is the name of the endeavour.

Museums are for society, for people. After saying 'It would not be unfair to say that the majority of curatorial staff are, in the museological sense, object orientated rather than people orientated', Hatton (1994:163) goes on to make the relevant comment 'We may be seeing the evolution of the museum, as a heritage agency, away from its original, predominantely objectcollecting base.'

On the whole consoling news for museums, and heritage and tourism, is delivered in the UK Museums \& Galleries Commission publication By Popular Demand: a strategic analysis of the market (Davies 1994:34). There is reference to the ageing of the population, and implication of the grey segment's taste for heritage/culture, in the statement 'Demographic movements are generally working in favour of museums and art galleries.' There is, however, the warning and prediction 'Those museums and art galleries which charge will continue to find it very difficult to maintain visit numbers.'

The critical role of museums in the appropriate communication and portrayal of heritage has been drawn attention to by Muller. He says (1997:7),

Diverse affinity and interest groups, as well as other "communities," have learned that the manner of presentation of their past and interpretation of their heritage have serious consequences for the present. 
32 As such, museums are far too important to remain on the periphery of policy development and many other aspects of community activity.

What this paper has examined - heritage, museums and their visitors or tourists - is a major society involvement and interest.

In catering to and satisfying society and the public of whom many or all are tourists according to the broad definition chosen, museums should make sure their heritage, of operation and subject, is not holding them back. Their balancing act, a difficult task, is to provide a choice of continuum between past, present and future. However, for the museum of calibre there should be nothing to fear from tourism as a potentially dominating influence either on its own heritage or on its presentations of heritage.

\section{REFERENCES}

Able, E.H: see below Partners in Tourism: Culture and Commerce 1997.

Area Museum Council for the South West and the West Country Tourist Board: Rain or Shine: $A$ Tourism and Museums Strategy, Taunton 1993.

Boyd, in Falk, J.H. \& Dierking, L. D: The Museum Experience, Washington D.C. 1992.

Davidson, T. L : 'What are travel and tourism: are they really an industry' in ed Theobold, W., Global Tourism : the next decade, Oxford 1992.

Davies, S: By Popular Demand: a strategic analysis of the market, London 1994.

Guggenheim Magazine (Fall 1997) as reported by Slessor in Architectural Review, London December 1997.

Hatton, A: 'The legislation and industrial context: museums' in ed Harrison, R., Manual of Heritage Management, Oxford 1994.
MacDonald, G.F., \& Alsford, S: A museum for the global village, Hull, Canada 1989.

McLuhan, M: Counterblast, London 1969.

Mulgan, G: Connexity: How to Live in a Connected World, London 1997.

Muller, H.N: in ed Wireman, P., Partnerships for Prosperity: Museums and Economic Development, Washington D.C. 1997.

Museums Association : The National Strategy for Museums. London June 1996.

Runyard, S : Museums and Tourism: Mutual benefit. London 1993.

Partners in Tourism: Culture and Commerce. ed Garfield, D., Washington D.C. 1997.

Sudjic, D: The 100 Mile City. London 1992.

Tunbridge, J.E. \& Ashworth, G. J: Dissonant Heritage: the management of the past as a resource in conflict. Chichester 1996.

World Decade of Cultural Development A practical guide to the World Decade of Cultural Development, 1988-97, Paris 1987.

World Wide Web : bm30.es/guggenheim July 1997.

World Wide Web : getty.edu/center/1gla_top $1 . h t m$ December 1997.

Paper presented at a meeting of the Danish Museums Association in March 1998.

Priscilla Boniface is Senior Lecturer in Travel and Tourism Marketing at the University of Northumbria. Her background is in heritage. For many years she worked for the Royal Commission on the Historical Monuments of England. Her most recent book is 'Managing Quality Cultural Tourism'. Adr $47 b$ Leazes Terrace, Newcastle upon Tyne, NE1 $4 L Z, U K$

E-mail: priscilla.boniface@unn.ac.uk 